\title{
Productivity and Preference of Salt Tolerant Boro Rice varieties in Saline Non-gher and Gher Ecosystems
}

\author{
Md Harunur Rashid ${ }^{1 *}$ and Shama Nasrin²
}

\begin{abstract}
Use of marginal coastal saline lands for rice cultivation is one of the options to sustain the net rice cropped area and rice production. On-farm farmer's participatory field trial was conducted in Bangladesh during 2012 and 2013 in non-gher and gher of medium saline ecosystems. The objective of the study was to identify suitable Boro variety for medium saline soils. Salt tolerant rice varieties, BRRI dhan 47 and Binadhan- 8 were evaluated along with widely adopted BRRI dhan28 in non-gher area. BRRI dha47, Binadhan-8 and Binadhan-10 were tested in saline ghers. Crops were irrigated with water of 1.89 to $3.5 \mathrm{dS}$ m-1 at different growth stages respectively. In saline non-gher, where soil salinity went up to $6.35 \mathrm{dS} \mathrm{m}^{-1}$, the highest grain yield was produced by Binadhan-8 $\left(4.57 \mathrm{t} \mathrm{ha}^{-1}\right)$ followed by BRRI dhan28 $\left(4.23 \mathrm{t} \mathrm{ha}^{-1}\right)$. The highest grain yield was recorded in Binadhan-10 (5.14 $\mathrm{t} \mathrm{ha}-$ $\left.{ }^{1}\right)$ in ghers which was 6 and $12 \%$ higher than BRRI dhan47 and Binadhan-8 respectively at soil salinity of $7.43 \mathrm{dS}$ $\mathrm{m}^{-1}$. Farmers preferred Binadhan-10 as a salt tolerant variety for its higher grain yield and medium grain quality.
\end{abstract}

Key words: Salt tolerant rice; Boro variety; medium saline fields; ghers

\section{INTRODUCTION}

Rice is the most important cereal crop in many Asian countries including Bangladesh. Water stagnation, salinization, erosion and human settlements lead to the loss of rice fields in an alarming speed in many of countries (Maclean et al., 2002). Densely populated country like Bangladesh desperately needs substantial increases in crop production to provide her teeming millions with food. The expanding area under crops especially the marginal land is one of the way of increasing crop production. The coastal saline soils make up the bulk of such land in Bangladesh (Panaullah, 1993). About 0.83 million hectares of the arable land of Bangladesh are affected by varying degrees of salinity (Karim et al., 1990), which increased to 1.09 million ha in recent years (SRDI, 2012). The larger portions of land of south western districts of the country are affected by salinity which is extended further by area and intensity after occurring of devastating tropical cyclones Aila and Sidr. Agricultural land use of this area is very poor, which is roughly $50 \%$ of the country's average (Petersen and Shireen, 2001).
The electrical conductivities (ECs) of the soil and water in the region remain as the lowest in July-August and the highest in March-April. The common trend is an increase in salinity with time, from November-December to MarchApril, until the onset of the monsoon rains. Experiencing the soil salinity pattern over the periods, single wet season rice (T. Aman) cropping sequence is dominant in the area. The fallow period of the dry and pre-monsoon season may be brought under cropping with the inclusion of salt tolerant crops variety.

The south western region is remarkably characterized by combination of normal crop land (non-gher) and ghers. Normal rice field is dominated by single T. Aman rice cropping sequence. On the contrary, land surrounded by large bunds mainly for shrimp and prawn cultivation is known as gher. Dry season rice (Boro) is mainly cultivated in this system followed by shrimp or prawn or carp or mix of this culture.

\footnotetext{
1Senior Scientific Officer, Rice Farming System Division, Bangladesh Rice Research Institute, Gazipur 1701. ${ }^{2}$ Agriculture Development Officer, IRRI, Bangladesh. * ${ }^{\circ}$ orresponding author's email: hrashid67@yahoo.com Productivity and Preference of Salt Tolerant Boro Rice 18
} 
As a salt sensitive crop rice yield is restricted in substantial areas of Africa and south and south-east Asia (Flowers and Yeo, 1981; Ponnamperuma, 1984). Rice varieties differ in their susceptibility to salinity due to its physiological mechanism to adjust to osmotic pressure (Yeo and Flower, 1984). The young seedlings and the plant at the flowering stage appear to be the most sensitive while tillering plants are less sensitive (Flowers and Yeo, 1981). In south-western Bangladesh, applying irrigation with stored surface water and ground water from shallow tube well farmers grow a popular modern variety, BRRI dhan 28 in Boro season in saline areas with a lower yield compared with that grown in non-saline areas. The salt tolerant variety adoption is urgent to cope with the situation and to increase the productivity of rice. Bangladesh Rice Research Institute (BRRI) recommended BRRI dhan47 as a salt tolerant variety which can tolerate salinity up to 12-14 $\mathrm{dS} \mathrm{m}^{-1}$ at seedling stage up to three weeks and $6 \mathrm{dS} \mathrm{m}^{-1}$ at all the growth stages and it has the potential to produce $1 \mathrm{t} \mathrm{ha}^{-1}$ yield compared to BRRI dhan28 (BRRI, 2012), Bangladesh Institute of Nuclear Agriculture (BINA) also recom-mended salt tolerant varieties, Binadhan- 8 and Binadhan-10 where soil salinity reaches up to $8-10 \mathrm{~d} \mathrm{~S} \mathrm{~m}^{-1}$ (BINA, 2012a, BINA 2012b). These varieties can tolerate similar soil salinity of BRRI dhan47 at the seedling stage. However, farmers' participatory evaluation of these varieties is lacking which may expedite faster adoption of the salt tolerant variety. Therefore, a study was conducted to identify suitable salt tolerant rice variety in Boro season through farmers' participatory approach.

\section{MATERIALS AND METHODS}

The farmers' participatory trial was conducted in six farmers' fields at Hatbati $\left(22^{\circ} 44^{\prime} \mathrm{N}\right.$ and $\left.89^{\circ} 30^{\prime} \mathrm{E}\right)$ and Sukdara $\left(22^{\circ} 67^{\prime} \mathrm{N}\right.$ and $\left.89^{\circ} 47^{\prime} \mathrm{E}\right)$ villages under Batiaghata upazila of Khulna district during the Boro season in 2012 and 2013 respectively. The study villages, Hatbati and Sukdara respectively, were selected as non-gher and gher, where wet season rice (T. Aman)-dry season rice (Boro) and fish (mixed species of carp and prawn)-rice (Boro) cropping systems were exist. The participatory lead farmers were selected through focus group discussion (FGD). Both the villages belong to the Ganges Tidal Floodplain soil of agro-ecological zone (AEZ) 13. The soils of the experimental fields at $0-15$ $\mathrm{cm}$ depth were clay loam and clayey in textures respectively. Salt tolerant rice varieties, BRRI dhan 47 and Binadhan-8 were evaluated along with the popular rice variety, BRRI dhan 28 at Hatbati. On the other hand, newly released Binadhan-10 was included with other salt tolerant varieties in the study conducted in the gher at Sukdara. The trial was designed as $\mathrm{RCB}$ design with disperse replications in six farmer's fields in both the years.

Rice seedlings were transplanted on 25 and 18 January with 35- and 33-day-old seedlings in 2012 and 2013 respectively. The experimental plots were prepared with three passes with twowheel tractor followed by two-laddering prior to transplanting. Two or three seedlings were used per hill maintaining $20 \mathrm{~cm}$ row and $20 \mathrm{~cm}$ plant spacing. Gap filling was done at seven days after transplanting where necessary. The fertilizer rates $\left(\mathrm{kg} \mathrm{ha}^{-1}\right)$ were $135 \mathrm{~N}, 20 \mathrm{P}, 27 \mathrm{~K}, 9$ $\mathrm{S}$ and $3 \mathrm{Zn}$. The total amounts of $\mathrm{P}$ as triple superphosphate, $\mathrm{K}$ as potassium chloride, $\mathrm{S}$ as gypsum and $\mathrm{Zn}$ as zinc sulfate were applied at the final land preparation. Nitrogen as urea was applied in three equal splits at 15-20, 30-35 and 45-50 days after transplanting (DAT). The crops were irrigated with surface water at the initial stage followed by ground water using shallow tube well. The salinity of the irrigation water was less than threshold level of salinity, $2 \mathrm{dS} \mathrm{m}^{-1}$ at Hatbati during whole of the growth period. On the other hand, it was recorded 1.89, 2.25, 2.50, 2.74 and $3.50 \mathrm{dS} \mathrm{m}^{-1}$ Sukdara at 15, 30, 45, 60 and 75 DAT respectively. Other crop management practices were done as per BRRI recommendation (BRRI, 2011). The crops were harvested at physiological maturity during 25 April to 2 May 2012 and 20 April to 2 May 2013.

Soil of $15 \mathrm{~cm}$ depth was collected before transplanting and at 15, 30, 45, 60, $75 \mathrm{DAT}$, and at the flowering stage from three spots of each plot and then made a composite sample and electrical conductivity was measured (LutronCD4301). Panicle number was counted from the sample area of $1 \mathrm{~m}^{2}$, taking three samples per plot. Grains were counted from 10 randomly selected panicles and mean value was used for 
comparison. The grain yield was recorded from three samples per plot having an area of 5 $\mathrm{m}^{2}$ and was adjusted to $14 \%$ moisture. The statistical analysis of the data was done using CropStat Version 7.2. Unless indicated otherwise, differences were considered significant only at P 0.05 . Economic analysis was performed to compare the performance of the salt tolerant varieties. The amount of different inputs required per hectare was calculated and the cost of input was estimated based on their local market price. Labour wage for different operations of crop cultivation was determined and included in the total variable cost (TVC). The farm gate price of paddy was used for calculating gross return (GR). The gross margin (GM) per hectare for each variety was calculated by deducting the total variable cost from the gross return. The preference ranking of the varieties was done allocating number against parameters determined by the male and female members of participating farmers.

\section{RESULTS AND DISCUSSION}

The tested rice varieties experienced soil salinity during different growth stages both in non-gher and ghers (Tables 1 and 2). Data revealed that all the varieties faced similar salinity at different growth stages both in non-gher and ghers. Rice grown in ghers faced higher soil salinity at all the stages compared to the normal rice fields might be due to use of brackish water for shrimp cultivation in the previous years (Table 2). The pre-planting soil salinity of the trial plots ranged from 3.40 to $3.75 \mathrm{dS} \mathrm{m}^{-1}$ and 4.35 to 4.75 $\mathrm{dS} \mathrm{m}^{-1}$ in non-gher and ghers respectively. The recorded soil salinity ranged from 4.28 to 4.30 dS $\mathrm{m}^{-1}$ at 15 DAT which was increased up to 6.17 to $6.35 \mathrm{dS} \mathrm{m}^{-1}$ at the flowering stage in rice fields at Hatbati. On the contrary, rice in ghers faced soil salinity from 5.11 to $5.18 \mathrm{dS} \mathrm{m}^{-1}$ at 15 DAT at Sukdara and was increased up to 7.43 $\mathrm{dS} \mathrm{m}^{-1}$ at the flowering stage (Tables 1 and 2).

Table 1. Soil salinity experienced by the salt tolerant rice varieties during the growth period in saline non-gher, Boro 2012

\begin{tabular}{l|c|c|c|c|c}
\hline \multirow{2}{*}{ Variety } & \multicolumn{5}{c}{ Soil salinity (dS m-1) } \\
\cline { 2 - 6 } & 15 DAT & 30 DAT & 45 DAT & 60 DAT & $\begin{array}{c}75 \text { DAT } \\
\text { (Flowering) }\end{array}$ \\
\hline Binadhan-8 & 4.30 & 4.65 & 4.86 & 5.39 & 6.17 \\
BRRI dhan47 & 4.30 & 4.66 & 4.88 & 5.34 & 6.35 \\
BRRI dhan28 & 4.28 & 4.66 & 4.84 & 5.52 & 6.24 \\
LSD 0.05 & $\mathrm{ns}$ & $\mathrm{ns}$ & $\mathrm{ns}$ & $\mathrm{ns}$ & $\mathrm{ns}$ \\
CV (\%) & 0.90 & 0.60 & 0.70 & 1.00 & 4.90 \\
\hline
\end{tabular}

ns=not significant.

Table 2. Soil salinity experienced by the salt tolerant rice varieties during the growth period in saline ghers, Boro 2013

\begin{tabular}{|c|c|c|c|c|c|}
\hline \multirow[t]{2}{*}{ Variety } & \multicolumn{5}{|c|}{ Soil salinity $\left(\mathrm{dS} \mathrm{m} \mathrm{m}^{-1}\right)$} \\
\hline & $15 \mathrm{DAT}$ & $30 \mathrm{DAT}$ & $45 \mathrm{DAT}$ & $60 \mathrm{DAT}$ & $\begin{array}{c}75 \mathrm{DAT} \\
\text { (Flowering) }\end{array}$ \\
\hline Binadhan-10 & 5.18 & 5.46 & 5.75 & 6.34 & 7.43 \\
\hline Binadhan-8 & 5.18 & 5.48 & 5.73 & 6.36 & 7.39 \\
\hline BRRI dhan47 & 5.11 & 5.47 & 5.76 & 6.33 & 7.38 \\
\hline $\operatorname{LSD}_{0.05}$ & ns & ns & ns & ns & ns \\
\hline CV (\%) & 1.40 & 1.50 & 1.50 & 1.90 & 1.10 \\
\hline
\end{tabular}

ns=not significant.

The tested varieties exerted significant effect on grain yield and yield components of panicle $\mathrm{m}^{-2}$, filled spikelet per panicle and 1000-grain weight (Tables 3 and 4). In non-ghers, the higher number of panicles $\mathrm{m}^{-2}$ was found in Binadhan$8\left(234 \mathrm{~m}^{-2}\right)$ and BRRI dhan $28\left(234 \mathrm{~m}^{-2}\right)$ compared to BRRI dhan47 $\left(220 \mathrm{~m}^{-2}\right)$ in rice fields. Similar trend was also observed in grains panicle ${ }^{-1}$. The 1000-grain weight (TGW) was recorded as the highest in Binadhan-8 which was at par with BRRI dhan47 but significantly higher than BRRI dhan28 (Table 3). Grain yield was the highest in Binadhan-8 (4.57 $\left.\mathrm{t} \mathrm{ha}^{-1}\right)$ followed by BRRI dhan28 (4.23 t ha-1) and the lowest grain yield 
was produced by BRRI dhan47 (4.05 $\left.\mathrm{t} \mathrm{ha} \mathrm{h}^{-1}\right)$. Results indicate that the higher panicle $\mathrm{m}^{-2}$, number of filled spikelet and heavier individual grain weight contributed to higher grain yield.

In ghers, the highest number of panicles $\mathrm{m}^{-2}$ was recorded in Binadhan-10 (243) which was significantly higher than Binadhan-8 and BRRI dhan47 (Table 4). BRRI dhan47 and Binadhan-8 produced comparable panicle $\mathrm{m}^{-2}$ (232 and 223 respectively). The number of grains panicle ${ }^{-1}$ followed the similar trend of panicle $\mathrm{m}^{-2}$ (Table 4). The TGW of BRRI dhan47 and Binadhan- 8 were similar which were significantly heavier than Binadhan-10 (Table 4). The highest grain yield was produced by Binadhan-10 (5.14 $\left.\mathrm{t} \mathrm{ha}^{-1}\right)$ followed by BRRI dhan $47\left(4.85 \mathrm{t} \mathrm{ha}^{-1}\right)$ and the lowest was from Binadhan-8 (4.62 $\left.\mathrm{t} \mathrm{ha}^{-1}\right)$. Irrespective of variety, the higher grain yield may be attributed to combined effect of higher panicle $\mathrm{m}^{-2}$, number of grains panicle $\mathrm{e}^{-1}$ and individual heavier grain weight. Variation in number of panicle $\mathrm{m}^{-2}$, grains panicle-1 and individual grain weight in different rice varieties in saline soils was also reported by Joseph and Mohanan (2013). The variety Binadhan-8 performed better in terms of grain yield compared to BRRI dhan47 in non-ghers under Rice-Rice cropping sequence whereas the contrast result was found in ghers under RiceFish cropping system. Irrespective of variety, the grain yield was higher in ghers under RiceFish system which may be attributed to early planting and higher fertility of soil where nutrients deposited from unused feed for fishes.

Among the tested varieties, Binadhan- 8 matured 1 to 3 days earlier than BRRI dhna47 (Tables 3 and 4). Binadhan-10 matured in 136 days in ghers which was significantly shorter than those of Binadhan-8 (142 days) and BRRI dhan47 (143 days).

Table 3. Growth duration, yield components and grain yield of salt tolerant varieties in saline non-gher, Boro 2012.

\begin{tabular}{lc|c|c|c|c}
\hline Variety & Growth duration (day) & $\begin{array}{c}\text { Panicle } \\
\mathrm{m}^{-2}\end{array}$ & $\begin{array}{c}\text { Filled spikelet } \\
\text { panicle }\end{array}$ & $\begin{array}{c}\text { 1000-grain wet (g) } \\
\text { Grain yield } \\
(\mathrm{t} / \mathrm{ha})\end{array}$ \\
\hline Binadhan-8 & 137 & 234 & 83.4 & 22.46 & 4.57 \\
BRRI dhan47 & 140 & 220 & 80.1 & 22.34 & 4.05 \\
BRRI dhan28 & 140 & 234 & 83.6 & 21.22 & 4.23 \\
LSD 0.05 & 2 & 6 & 1.6 & 0.25 & 0.14 \\
CV (\%) & 0.9 & 1.9 & 1.3 & 0.8 & 2.3 \\
\hline
\end{tabular}

ns=not significant.

Table 4. Growth duration, yield components and grain yield of salt tolerant varieties in saline ghers, Boro 2013.

\begin{tabular}{l|c|c|c|c|c}
\hline Variety & Growth duration (day) & $\begin{array}{c}\text { Panicle } \\
\mathrm{m}^{-2}\end{array}$ & $\begin{array}{c}\text { Filled spikelet } \\
\text { panicle- }\end{array}$ & $\begin{array}{c}\text { 1000-grain wt (g) } \\
\text { Grain yield } \\
(\mathrm{t} / \mathrm{ha})\end{array}$ \\
\hline Binadhan-10 & 136 & 243 & 124 & 22.20 & 5.14 \\
Binadhan-8 & 142 & 223 & 109 & 23.47 & 4.62 \\
BRRI dhan47 & 143 & 232 & 116 & 23.57 & 4.85 \\
LSD 0.05 & 1 & 10 & 9 & 0.38 & 0.14 \\
CV (\%) & 0.3 & 3.4 & 5.7 & 1.3 & 2.2 \\
\hline
\end{tabular}

ns=not significant.

Tables 5 and 6 show that production cost of Boro rice cultivation which ranged from $\mathrm{U} \$ 768$ to 776 ha-1 in non-gher area in 2012. On the other hand, production cost was recorded higher in ghers at Sukdara (\$828 ha-1) in 2013 which was due to increasing input price and labour wages. The higher gross return was recorded in Binadhan-8 (\$ 858 ha $\left.^{-1}\right)$ and BRRI dhan28 (\$881 ha-1) compared to BRRI dhan47 $\left(\$ 793 \mathrm{ha}^{-1}\right)$ in saline non-gher. In contrast, the gross return was recorded higher in BRRI dhan47 (\$ 983 ha $^{-1}$ ) compared to Binadhan-8 (\$ $\left.935 \mathrm{ha}^{-1}\right)$ in ghers. The highest gross return was earned from Binadhan-10 (\$ $\left.1107 \mathrm{ha}^{-1}\right)$. The

\section{Rashid and Nasrin}


higher grain yield resulted higher return. The gross margin and BCR showed similar trend of gross return in both the growing systems (Tables 5 and 6). In ghers, the highest BCR was recorded in Binadhan-10 (1.34) followed by
BRRI dhan47 (1.19) and the lowest in Binadhan8 (1.13). Irrespective of variety, the higher gross margin and BCR was found in ghers because of higher grain yield with a little cost.

Table 5. Economic return of salt tolerant varieties in saline non-gher, Boro 2012

\begin{tabular}{l|c|c|c|c}
\hline Variety & $\begin{array}{c}\text { Total variable cost }(\$ \\
\left.\text { ha }^{-1}\right)\end{array}$ & $\begin{array}{c}\text { Gross return } \\
\left(\$ \mathrm{ha}^{-1}\right)\end{array}$ & $\begin{array}{c}\text { Gross margin } \\
\left(\$ \mathrm{ha}^{-1}\right)\end{array}$ & BCR \\
\hline Binadhan-8 & 775 & 858 & 83 & 1.11 \\
BRRI dhan47 & 768 & 793 & 25 & 1.03 \\
BRRI dhan28 & 776 & 881 & 105 & 1.09 \\
\hline
\end{tabular}

Paddy price US\$ $\mathrm{t}^{-1}$ : BRRI dhan28=200, BRRI dhan47=187.5, Binadhan- $8=187.5$.

Table 6. Economic return of salt tolerant varieties in saline ghers, Boro 2013

\begin{tabular}{l|cc|c|c}
\hline Variety & $\begin{array}{c}\text { Total variable cost }(\$ \\
\left.\text { ha }^{-1}\right)\end{array}$ & $\begin{array}{c}\text { Gross return } \\
\left(\$ \text { ha }^{-1}\right)\end{array}$ & $\begin{array}{c}\text { Gross margin } \\
\left(\$ \text { ha }^{-1}\right)\end{array}$ & BCR \\
\hline Binadhan-10 & 828 & 1107 & 279 & 1.34 \\
Binadhan-8 & 828 & 935 & 107 & 1.13 \\
BRRI dhan47 & 828 & 983 & 155 & 1.19 \\
\hline
\end{tabular}

Paddy price US $\mathrm{t}^{-1}$ : BRRI dhan $47=200$, Binadhan $-8=200$, Binadhan $-10=212.5$.

In saline non-ghers, farmers' preference score for grain yield was the highest for Binadhan-8 (Table 7) and was the same for BRRI dhan 28 and BRRI dhan47. The overall score was the highest for BRRI dhan28 which was mainly higher market price for preferable grain size. The farmers opined that BRRI dhan28 was not affected in the study village like other saline areas as irrigated with below thresh hold level of salt water. In saline ghers, Binadhan-10 ranked first due to higher score for grain yield, grain number panicle ${ }^{-1}$, grain size and market price and salt tolerance. In saline rice field situation with soil salinity up to $6.35 \mathrm{dS} \mathrm{m}^{-1}$ with the provision of fresh water irrigation farmers were not convinced to grow salt tolerant rice variety with bolder grain. On the contrary, they preferred salt tolerant variety, Binadhan-10 in saline ghers. Saleque et al. (2005) also reported that the farmers' preference for salt tolerant variety varied on gradient of salinity.

Table 7. Preference ranking of salt tolerant varieties in saline non-gher and ghers, Boro 2012, Khulna

\begin{tabular}{|c|c|c|c|c|c|c|}
\hline \multirow[t]{2}{*}{ Parameter } & \multicolumn{3}{|c|}{ Saline rice field } & \multicolumn{3}{|c|}{ Saline gher } \\
\hline & BRRI dhan28 & BRRI dhan47 & Binadhan-8 & Binadhan-10 & Binadhan-8 & BRRI dhan47 \\
\hline Salt tolerance & 8 & 9 & 8 & 9 & 8 & 8 \\
\hline Grain yield & 7 & 7 & 8 & 9 & 7 & 7 \\
\hline Field duration & 8 & 7 & 8 & 8 & 7 & 7 \\
\hline Grain panicle $^{-1}$ & 8 & 7 & 7 & 8 & 7 & 7 \\
\hline Insect infestation & 7 & 8 & 8 & 8 & 8 & 8 \\
\hline Grain size & 8 & 7 & 7 & 8 & 7 & 7 \\
\hline Market price & 8 & 7 & 7 & 8 & 7 & 7 \\
\hline Score & 54 & 52 & 53 & 58 & 51 & 51 \\
\hline Rank & 1 & 3 & 2 & 1 & 2 & 2 \\
\hline
\end{tabular}




\section{CONCLUSIONS}

From the varietal performance of agro-economic productivity and farmers' preference, Binadhan10 could be disseminated in the similar salt affected ghers. Meanwhile, it might be tested in saline rice fields with high salinity and lacking fresh water irrigation.

\section{ACKNOWLEDGMENT}

We highly appreciate USAID for funding the study through the Cereal System Initiative for South Asia (Bangladesh).

\section{REFERENCES}

BINA (Bangladesh Institute of Nuclear Agriculture). 2012a. Modern Rice Cultivation Technique for Salt Tolerant Boro Rice Variety, Binadhan-8. Bangladesh Institute of Nuclear Agriculture, Mymensinsingh-2202. Bnagladesh.

BINA (Bangladesh Institute of Nuclear Agriculture). 2012b. Modern Rice Cultivation Technique for Salt Tolerant Boro Rice Variety, Binadhan-10. Bangladesh Institute of Nuclear Agriculture, Mymensinsingh-2202, Bangladesh.

BRRI (Bangladesh Rice Research Institute). 2011. Modern Rice Cultivation. Bangladesh Rice Research Instute, Gazipur 1701. 16:8-60.

BRRI (Bangladesh Rice Research Institute). 2012. Modern Rice Cultivation Technique for Salt Tolerant Boro Rice Variety, BRRI dhan47. Bangladesh Rice Research Institute, Gazipur 1701, Bangladesh.

Flowers, T J and A R Yeo. 1981. Variability in the resistance of sodium chloride salinity within rice (Oryza sativa L.) varieties. New Phytologist. 88:363-373.
Joseph, E A and K V Mohanan. 2013. A study on the effect of salinity stress on the growth and yield of some native rice cultivars of Kerala state of India. Agriculture, Forestry and Fisheries. 2(3):141-150.

Karim, Z, S G Hussain and M Ahmed. 1990. Salinity problems and crop intensification in the coastal region of Bangladesh. Bangladesh Agricultural Research Council, Dhaka. 33:3-5

Maclean, J L, D C Dawe, B Hardy and G P Hattel. 2002. Rice Almanac. III Edition. CABI Publishing, Walligford, Oxon. p. 253.

Panaullah, G M. 1993. Soil salinity and associate problems in connection with crop production in the coastal regions of Bangladesh. In: BRRI, editor. Proceedings of the workshop on coastal salinity and crop production in Bangladesh, 17 February, BRRI, Gazipur. p. 30.

Petersen, L and S Shireen. 2001. Soil and water salinity in the coastal area of Bangladesh. Soil Resources and Development Institute, Bangladesh.

Ponnamperuma, F N. 1984. Role of cultivar tolerance in increasing rice production on saline lands. In: Staples RC, Toenniessen GA, editors. Salinity Tolerance in Plants: Strategies for Crop Improvement, Wiley International, New York. pp. 255-271.

Saleque, M A, N N Choudhury, S M R Karim and G M Panaullah. 2005. Mineral nutrition and yield of four rice genotypes in the farmers' fields of salt-affected soils. J Plant Nutrition. 28:865-875.

SRDI (Soil Resources and Development Institute). 2012. Saline Soils of Bangladesh. Soil Resources and Development Institute, Mrittika Bhaban, Krishi Khamar Sarak, Dhaka-1215. pp.6-7.

Yeo, A R and T J Flowers. 1984. Mechanisms of salinity resistance in rice and their role as physiological criteria in plant breeding. In: Staples RC, Tooeniessen GA, editors. Salinity tolerance in plant: Strategies for crop improvement, Wiley International, New York 